mais” [“...Quin etiam existentia necessaria est revera in Deo proprietas strictissimo modo sumpta, quia illi soli competit, \& in eo solo essentiae partem facit” (Descartes 3, VII, 382-3); “Mais, bien davantage, l'existence nécessaire est vraiment en Dieu une propriété prise dans le sens le moins étendu, parce qu'elle convient à lui seul, et qu'il n'y a qu'en lui qu'elle fasse partie de l'essence." (Descartes 3, tomo II, p. 830)].

2. Acerca da existência atual, podemos dizer, com base nos textos cartesianos, que ela não constitui uma condição da representação do que quer que seja, e, portanto, que a predicação não faz suposição de existência, mas apenas de realidade (seja ela a realidade que uma quimera tem pelo fato de ser um objeto de pensamento ou aquela realidade em sentido pleno para um pensamento essencialista, que é a realidade da essência imutável das coisas). E se a predicação não faz suposição de existência, Descartes pode defender, sim, que a existência é uma perfeição - ainda que, não obstante, ele pareça recuar dessa sua posição no debate com Gassendi. Mas trata-se apenas de um recuo dialético, imposto pelos termos do debate. Além disso, contra a redução ao absurdo que Gassendi apresenta para refutar a tese cartesiana de que a existência é uma propriedade, pode-se aduzir outra diferença nos pressupostos, a saber, a de que, enquanto Gassendi aceitava a lógica aristotélica tradicional, buscando tão-somente aperfeiçoá-la (lógica essa fundada na extensão e sobre a qual repousa, por sua vez, a doutrina mesma dos predicáveis), Descartes critica em termos epistêmicos a obscuridade do conteúdo das noções e dos conceitos das classes que formam os gêneros e as espécies nesta lógica da extensão (Descartes 3, Recherche de la vérité, $515 ; 516$ ), e empreende a substituição da lógica aristotélica por outra lógica, derivada do tipo de raciocínio matemático, que se baseia fundamentalmente na intuição de naturezas simples e comuns. A importância disso tudo é que, já que o autor não era obrigado a adotar pressupostos diferentes dos seus e que a crítica de Gassendi permaneceu uma crítica externa, por assim dizer, Descartes poderia manter, apesar das criticas de Gassendi, a tese de que a existência é uma propriedade (e desta tese decorre como conseqüência, no pensamento de Descartes, que a analogia da prova ontológica com as demonstrações matemáticas é bem fundada, e, sendo assim, que a prova ontológica é tão certa quanto uma demonstração matemática). Mais detalhes sobre isso, consulte nossa tese de doutoramento "Testando a Validade e o Status do ‘Argumento Ontológico’ no Sistema Cartesiano”, defendida em dezembro de 2008.

\section{DA FÍSICA DO INTENSIVO A UMA ESTÉTICA DO INTENSIVO: DELEUZE E A ESSÊNCIA SINGULAR EM ESPINOSA}

Cíntia Vieira da Silva*

Resumo: A noção de intensidade é de extrema importância para o pensamento deleuziano, fazendo-se presente não apenas na elaboração de sua própria filosofia da diferença, como também nas leituras que faz dos outros filósofos que lhe são caros, especialmente na sua reconstrução do espinosismo. Deleuze concebe a essência singular espinosana em termos intensivos. Sendo assim, este artigo procura reunir elementos para mostrar a importância da noção de intensidade no projeto deleuziano de unificação dos dois sentidos de estética e o papel do uso de concepções de extração espinosista na empresa deleuziana. Estes apontamentos deixam implícito um outro tema: o da possibilidade de elaborar uma Estética a partir de Espinosa, vale dizer, uma Estética atenta a sua ancoragem corporal.

Palavras-chave: Espinosa, Deleuze, Estética, Intensidade, Corpo.

É conveniente que um título indique o tema a ser desenvolvido no texto ou exposição que ele nomeia, mantendo, entretanto, um certo mistério, criando um certo enigma que desperte a curiosidade do auditório ou dos leitores. Pareceu-me conveniente, então, fazer referência ao título do livro de François Zourabichvilli, Spinoza; une physique de la pensée, tentando criar uma outra junção que fosse tão surpreendente quanto aquela entre física e pensamento ${ }^{1}$, ao mesmo tempo em que expressasse de modo conveniente a linha a ser seguida no artigo. Sob pena de me exceder no didatismo, explicito e desfaço o mistério contido no título.

Se pensarmos no sentido que a palavra Física toma a partir do século XVII, no sentido em que a empregamos para designar uma ciência particular que estuda as leis universais que explicam o comportamento dos

* Professora Adjunta do Departamento de Filosofia da Universidade Federal de Ouro Preto. 
corpos (seu movimento, os fenômenos óticos que neles se produzem, as forças de atração entre eles e assim por diante), tenderemos a delimitar o campo da Física como sendo o da extensão. Conseqüentemente, pensaremos que a Física lida com certas qualidades e as grandezas escalares que nelas se podem verificar. Desse ponto de vista, e acompanhando a terminologia espinosana, enxergaríamos os corpos como conjuntos de partes exteriores umas às outras, unidas entre si segundo uma determinada relação característica. Sabemos, contudo, que estas duas dimensões não esgotam a concepção espinosana da individualidade.

Além das partes extensas e das relações de movimento e de repouso entre elas, os indivíduos são igualmente expressões de uma essência singular. Se quisermos, portanto, estudar inteiramente a Natureza a partir dos indivíduos que a compõem, retomando um sentido mais antigo de Física, não podemos negligenciar tais essências singulares. Ora, Deleuze compreende esta dimensão da individualidade em função de uma teoria do intensivo na qual mobiliza filósofos como Duns Scoto e Kant. Os corpos são partes extensivas ou extrínsecas do atributo da extensão, ao passo que as essências singulares são partes intensivas ou intrínsecas de todos os atributos da substância. Assim sendo, meu propósito aqui é reconstituir os passos que permitem a Deleuze compreender a essência singular como intensidade ou quantidade intensiva, o que lhe permite caracterizá-la também como grau de potência. A partir desta reconstituição, será possível ao menos indicar o papel que o conceito de intensidade desempenha na economia do pensamento deleuziano, tanto no que se refere à realização do projeto de unificar os dois sentidos de estética, formulado em Diferença e repetição, de pensar as obras de arte de modo imanente, ou seja, buscando mostrar que novas maneiras de sentir elas produzem, quanto no que se refere à ontologia da diferença. É que as intensidades são, por assim dizer, as unidades mínimas da diferenciação tanto no que se refere aos processos de individuação (produção na natureza), quanto à criação artística. Aliás, esta repartição recobre uma unidade, ou seja, não há distinção substancial entre produção natural e criação artística, cada uma delas sendo modos de produção de singularidades (processos de individuação na natureza ou na arte).

Em Spinoza et le problème de l'expression, Deleuze insere a noção de intensidade numa interpretação que visa mostrar que as essências singulares são realidades físicas, sendo, portanto, dotadas de existência. Sua existência, contudo, não se identifica à existência dos modos correspondentes, assim como elas não se caracterizam como meras "possibilidades lógicas", nem como "estruturas matemáticas", nem como "entidades metafísicas" (Deleuze 3, p.174). A existência atual das essências deriva de sua causa, ou seja, é por serem produzidas por Deus que as essências dos modos têm uma existência que não pode ser reduzida à categoria da possibilidade, tanto assim que todas as essências convêm entre si ou se compõem, na medida em que todas têm Deus como causa. Por isso, partimos de uma interpretação que considera os atributos como qualidades eternas e infinitas, que, enquanto tais, são indivisíveis, por um lado, e como dotados de quantidades, por outro. Tais quantidades podem comportar partes, vale dizer, podem ser consideradas como divisíveis. Deleuze entende que, na Ética, a palavra "partes" deve ser tomada em dois sentidos.

Assim, devemos falar de partes extensas, ou extensivas, e partes intensivas. Ao contrário do que se poderia imaginar, as partes extensas não são apenas unidades da extensão. Na leitura deleuziana, a extensividade pode ser aplicada a todos os atributos. No caso do pensamento, suas partes extensas seriam as idéias que correspondem aos corpora simplissima (partes extensivas da extensão) ${ }^{2}$. Quanto às partes intensivas, devem ser entendidas como graus de potência ou de intensidade, em que um 
atributo se divide modalmente, ou seja, em partes modais e não reais ou substanciais. segundo o tema de uma variação das qualidades que não se dá por mudança formal ou essencial, recorrente ao longo dos séculos XIII e $\mathrm{XIV}$, em debates, travados notadamente no interior do scotismo, em torno do modo intrínseco ou grau. Tais questões concernem a possibilidade de uma qualidade "ser afetada por graus diversos", mantendo, no entanto, a mesma essência ou razão formal. Outra questão, correlativa a esta, seria a de saber se estas afecções se refeririam à essência ou "apenas à existência" (Deleuze 3, p.173, nota 2) ${ }^{3}$. Nessa perspectiva, cada atributoqualidade tem uma quantidade infinita divisível sob certas condições que teria modos intrínsecos ou graus.

Deleuze não esconde o caráter interpretativo desta solução, tanto assim que afirma que "sem desenvolver explicitamente esta teoria, Espinosa se orienta em direção à idéia de uma distinção ou de uma singularidade própria às essências de modos enquanto tais" (Deleuze 3, p.180 [tradução minha]). Há uma dupla distinção que afeta "as essências de modos": em relação ao "atributo, como a intensidade da qualidade e entre si, tal como os diversos graus de intensidade" (Deleuze 3, p.179-180). Mas a distinção intrínseca das essências não muda a natureza do atributo, o qual mantém sua univocidade. Se Deleuze recorre à teoria de uma distinção intrínseca no interior das qualidades, elaborada por Duns Scoto; se enxerta em sua leitura de Espinosa um vocabulário que não é empregado por este, isto se deve à necessidade de compreender as essências singulares como sujeitas ao processo de individuação, tanto quanto os modos, mas de uma maneira diferente.

Mas o que impediria entender que as essências constituem uma dimensão da individualidade ou um tipo de individuação? Ocorre que, por serem todas submetidas a um mesmo princípio de produção, as essências, nas palavras de Deleuze "compõem um sistema total, um conjunto atualmente infinito" (Deleuze 3, p.177), não podendo, deste ponto de vista, ser separadas umas das outras. No entanto, a seqüência do texto citado pergunta-se a respeito de uma possibilidade de distinção entre as essências, a qual deve ser encontrada para que estas possam ser dotadas de uma existência ou realidade física, como dito anteriormente. A dificuldade de resolver tal questão é atestada pelo fato de o Breve Tratado não conter sequer ainda um equacionamento claro do problema correspondente. Os textos em que tal problema aparece contêm uma ambigüidade que permitirá a Deleuze neles apoiar sua solução. Seu argumento se sustenta numa diferenciação entre "estar contido" e "se distinguir". Isto quer dizer que o fato de as essências estarem contidas na substância enquanto o modo não exista não acarreta uma impossibilidade de distinguir tais essências. No entanto, esta distinção não é extrínseca.

Uma individuação extrínseca se faz através da duração, pela figura e pelo lugar, e corresponde ao que ocorre aos modos. A existência do modo, na medida em que lhe confere uma duração, faz com que deixe "de estar simplesmente contido no atributo" (Deleuze 3, p.179), assim como não permite que sua idéia continue a estar apenas compreendida na idéia de Deus. Deleuze recorre a uma metáfora, utilizada já por Duns Scoto, para explicar a diferença entre as distinções extrínseca e intrínseca. Segundo tal imagem, a substância seria uma muralha cujo atributo/cuja qualidade seria a brancura. Os modos, como distinções extrínsecas, seriam figuras que se desenham sobre a muralha branca. Mas, antes do aparecimento dessas figuras, já haveria uma distinção interna à própria brancura, ou seja, uma distinção dela, a saber, a intensidade (da brancura) e uma distinção nela, qual seja: (seus) os diversos graus de intensidade. A muralha branca sem figuras alude a um "estado" em que "a qualidade não é afetada por (qualquer)/ alguma coisa que se (distinga)/distinguiria dela extrinsecamente" (Deleuze 3, p.179). Mas é justamente neste estado que se deve procurar por um 
princípio de individuação intrínseco, de modo que possamos pensar a distinção extrínseca dos modos como derivada da distinção intrínseca entre suas essências. $\mathrm{O}$ caráter intrínseco desta distinção permite manter a univocidade da substância e de seus atributos, além de propiciar uma exposição da gênese do processo de individuação, na medida em que seu princípio é interno à existência das próprias essências dos modos.

Para retomar o quadro completo da série que vai da substância aos atributos, e em seguida, aos modos intrínsecos ou essências e aos modos extrínsecos, retomo o final do capítulo aqui estudado:

“a substância é como a identidade ontológica absoluta de todas as qualidades, a potência absolutamente infinita, (da) potência de existir sob todas as formas e de pensar (sob) todas as formas; os atributos são as formas ou qualidades infinitas, como tais indivisíveis. O finito, portanto, não é nem substancial, nem qualitativo".

"Cada qualidade substancial tem uma quantidade modalintensiva, ela mesma infinita, que se divide atualmente em uma infinidade de modos intrínsecos. Esses modos intrínsecos, contidos todos juntos no atributo, são as partes intensivas do próprio atributo. Por isso mesmo, eles são partes da potência de Deus, sob o atributo que os contém”. (Deleuze 3, p.181)

Diante desta citação, cabe observar que a assimilação entre a essência dos modos e um grau da potência da Natureza permite a Deleuze não apenas estreitar os nós que, a seu ver, unem Espinosa e Nietzsche numa grande identidade, como também desenvolver aspectos de sua teoria do desejo, notadamente a noção de Corpo sem órgãos. Desenvolver esta observação nos desviaria do tema aqui em pauta, assim sendo, resta finalizar esta passagem por Spinoza et le problème de l'expression, uma vez que já foi delineada a construção da interpretação das essências dos modos como intensidades, bem como respondida a questão a respeito do ganho conceitual, interno ao espinosismo, de uma tal interpretação. No entanto, já se aludiu aqui a uma outra motivação, exterior à compreensão do texto de Espinosa, que leva Deleuze a elaborar esta compreensão. Esta motivação será melhor explicitada se recorrermos a Diferença e repetição, tese principal defendida por Deleuze concomitantemente à que viria a constituir o primeiro de seus livros em torno de Espinosa, sua tese secundária (Mengue 6, p.295).

O grande tema que preside a investigação empreendida em Diferença e repetição é desenvolver um conceito da diferença por si mesma, sem passar pelas figuras do negativo, tais como a oposição. A esta pesquisa conceitual corresponde uma indagação ontológica que redunda numa concepção do ser como diferenciação complexa. Mas esta ontologia permaneceria abstrata e engendraria uma concepção do pensamento presa aos pressupostos da representação se não se desdobrasse numa gênese da diferença que se fizesse ao mesmo tempo no real e no pensamento, mostrando como esta dupla geração se refere a modos de uma só produção. O pensamento, para atender a tais requisitos, deveria ser igualmente objeto de uma dupla gênese, referente às instâncias objetivas e subjetivas, ou seja, uma gênese que mostre como subjetivações são constituídas no dado e como o dado se constitui e produz objetivações nessas subjetivações. Vejamos como a noção de intensidade se insere nesta perspectiva genética.

Logo no início do Capítulo V de Diferença e repetição, intitulado Síntese assimétrica do sensível, Deleuze afirma que "a intensidade é a forma da diferença como razão do sensível. Toda intensidade é diferencial, diferença em si mesma" (Deleuze 1, p.356; orig. p.287). Isto significa que a intensidade constitui a condição do aparecimento de qualquer fenômeno, significa que só percebemos as qualidades e quantidades extensivas 
porque, sob elas, podemos antecipar as diferenças de intensidade, os graus ou quantidades intensivas das qualidades. Valendo-se de noções advindas da Física, mais especificamente da energética, Deleuze considera a intensidade como diferença de potencial ou disparidade. Do ponto de vista da energética, uma energia se define sempre em função de um elemento intensivo e outro extensivo, como se pode ver no caso da "energia linear", que se define através da força e do comprimento, ou da "energia de superfície", que depende da tensão superficial e da superfície, ou ainda da "energia de volume", que resulta da pressão e do volume. A mesma lógica valeria para a relação entre energia gravitacional, peso e altura, assim como para a relação entre energia térmica, temperatura e entropia (cf. Deleuze 1, p.357; orig. p.287).

Estes exemplos são utilizados para explicar a dificuldade de se pensar uma qualidade intensiva, uma vez que, na experiência, a intensidade apareceria sempre sob as qualidades e desdobrada na extensão. Esta dificuldade de perceber a intensidade e, por conseguinte, de pensá-la, deriva de seu próprio desdobramento, que tende a anular as diferenças. Nas palavras de Deleuze:

\begin{abstract}
"a intensidade se explica, desenvolve-se numa extensão (extensio). É essa extensão que se refere ao extenso (extensum), onde ela aparece fora de si, recoberta pela qualidade. A diferença de intensidade anula-se ou tende a se anular nesse sistema; mas é ela que, explicando-se, cria esse sistema".(Deleuze 1, p.364-365; orig. p.294)
\end{abstract}

Percebe-se, neste ponto, uma estrita correlação entre a implicação da intensidade em si mesma, que se mantém mesmo quando ela se desdobra na extensão, e a individuação das essências contidas (ou, para repetir o mesmo termo, implicadas) nos atributos, em particular na extensão e no pensamento, a distinção entre as idéias das essências individuais dos modos no interior das idéias de Deus e a maneira pela qual elas se mantêm mesmo quando os modos passam a existir na duração e na extensão.

O próprio espaço extensivo ou extensio gera-se a partir de um espaço intensivo ou Spatium, como já se anunciava na dupla interpretação dos atributos desenvolvida em Spinoza et le problème de l'expression. Deleuze emprega neste ponto um vocabulário kantiano, sem deixar, contudo, de se contrapor a algumas posições de Kant e de propor articulações conceituais diferentes das kantianas. Num texto anterior a Diferença e repetição, intitulado $A$ idéia de gênese na estética de Kant, Deleuze já expunha seu interesse por uma perspectiva genética inaugurada no estudo do sublime. No caso do sublime, Kant mostrava como um livre acordo entre as faculdades podia ser engendrado sem que uma faculdade legisladora estivesse previamente determinada. A Crítica da faculdade de julgar explica, portanto, como se torna possível que uma determinada faculdade se torne legisladora, dependendo do interesse em questão. Nas palavras de Deleuze:

"Com efeito, é este o sentido da Crítica da faculdade de julgar: sob as relações determinadas e condicionadas das faculdades, ela descobre o livre acordo indeterminado, incondicionado. Ora, jamais uma relação determinada de faculdades, condicionada por uma dentre elas, seria possível se não fosse primeiro tornado possível por este livre acordo incondicionado. Igualmente, a Crítica da faculdade de julgar não se atém ao ponto de vista do condicionamento tal como aparecia nas duas outras Críticas: ela nos faz entrar na Gênese.” (Deleuze 2, p.86-87)

Mas o elogio ao kantismo torna-se crítica a partir do momento em que Deleuze aponta a insuficiente expansão da perspectiva genética. Tal 
perspectiva não se deveria limitar ao sublime ou aos juízos de gosto, mas deveria chegar às condições de possibilidade da experiência real, anteriores às formas puras do espaço e do tempo, as quais também deveriam ser objeto de uma gênese. É o que Deleuze procura fazer no capítulo de Différence et répetition, intitulado La synthèse assimétrique du sensible.

Se assumirmos um ponto de vista deleuziano neste caso, poderíamos dizer que Kant é tão mais repreensível, quanto mais já havia conceituado o elemento que poderia ter permitido um aprofundamento da perspectiva genética. Tal elemento é justamente a intensidade, que aparece na Crítica da razão pura como uma das antecipações da percepção. A parte intitulada "Antecipações da percepção" se insere na Analítica dos princípios, segundo livro da Lógica transcendental. Antes que a percepção se configure como intuição, que se refere a grandezas extensivas, conforme Kant afirma nos Axiomas da intuição, há uma antecipação da percepção que se refere "à síntese da produção da quantidade de uma sensação a partir do seu início" (Kant 6, B 208). Antes de referir a sensação a um objeto, a sensibilidade é afetada por ele e registra, por assim dizer, uma grandeza intensiva que corresponde ao grau ou intensidade dessa afecção. O princípio das antecipações da percepção é enunciada por Kant da seguinte maneira: "em todos os fenômenos o real, que é objeto de sensação, tem uma grandeza intensiva, isto é, um grau” (Kant 6, B 207). A sensação não comporta grandeza extensiva porque não é uma representação objetiva, como a intuição, mas apenas subjetiva, referindose à afecção. A quantidade da sensação se produz, assim, a partir de um grau zero, equivalente à ausência de sensação ou afecção.

Para Deleuze, no entanto, a intensidade não se reduz a uma antecipação da percepção, mas é ela que engendra tanto os esquemas como extensio, a grandeza extensiva como extenso, a "qualitas como matéria ocupante do extenso e" o "quale como designação de objeto" (Deleuze
1, p.370; orig. p.298). Deleuze chama esse desdobramento de "estética das intensidades" (Deleuze 1, p.390; orig. p.315), que corresponde a um movimento de atualização das Idéias, entendidas como "multiplicidades virtuais" (Idem ibidem). É o que se pode depreender do trecho a seguir:

"Como é a Idéia determinada a encarnar-se em qualidades diferenciadas, em extensos diferenciados? Que é que determina as relações que coexistem na Idéia a se diferenciarem em qualidades e extensos? A resposta é dada precisamente pelas quantidades intensivas. O determinante no processo de atualização é a intensidade. É a intensidade que dramatiza. É ela que se exprime imediatamente nos dinamismos espaço-temporais de base e que determina uma relação diferencial, 'indistinta' na Idéia, a encarnarse numa qualidade distinta e num extenso distinguido". (Deleuze 1, p.391-392; orig. p.316)

Os dinamismos espaço-temporais virão a constituir um dos elementos mais importantes na nova teoria da individuação que, em Mille plateaux, delineia um dos aspectos da teoria das multiplicidades. Com Guattari, Deleuze procura conceituar um tipo de individuação, anterior à formação de sujeitos e objetos, que seria a individuação por hecceidade.

Esta teoria da individuação prolifera referências à literatura, à música, indicando que a produção de indivíduos, de acontecimentos não deriva apenas do plano de imanência da Natureza, mas preside a construção dos planos de composição de outras maneiras de pensar que não a filosófica. Deleuze e Guattari mencionam as hecceidades produzidas por Virgínia Woolf, D.H. Lawrence, William Faulkner, Michel Tournier, Charlotte Brontë, Kleist, Hölderlin, Proust, no campo da literatura. Mas também se referem à música de Ravel, Debussy, Chopin, Wagner, Schummann e Bethoven, a partir das análises que Pierre Boulez, maestro, compositor 
e teórico da música, apresenta em seu Par volonté et par hasard, além de apontarem o trabalho de John Cage (cf. Deleuze \& Guattari 4, plateau 10, passim). Assim, aquilo que poderíamos chamar de uma ontologia do devir apenas se concretiza aliando-se a uma estética das hecceidades. Ambas as noções, devir e hecceidade, transitam livremente de uma teoria da arte para uma teoria das multiplicidades, substituto de uma teoria do ser. A composição entre hecceidades se faz segundo o modo do devir, que toma o lugar da mimese na teoria da arte, e de um ser idêntico a si mesmo na teoria das multiplicidades.

A definição de hecceidade aparece no décimo platô, Devir-intenso, devir-animal, devir-imperceptível, num trecho intitulado Lembranças de uma hecceidade. Entretanto, alguns elementos desta definição já são antecipados em trechos anteriores, como nas Lembranças de um teólogo. Neste trecho, Deleuze e Guattari afirmam que "um grau, uma intensidade é um indivíduo, Hecceidade, que se compõe com outros graus, outras intensidades para formar um outro indivíduo" (Deleuze \& Guatari 4, p.310). Há, neste ponto, uma assimilação entre hecceidades e a noção de formas acidentais, que se distinguem tanto de formas essenciais imutáveis, quanto dos sujeitos constituídos a partir destas. As formas acidentais podem ser consideradas como hecceidades ou intensidades porque comportam graus, "são suscetíveis de mais e de menos" (Deleuze \& Guattari 4, p.309). Deleuze e Guattari explicam que

"um grau de calor é um calor perfeitamente individuado que não se confunde com a substância ou o sujeito que a recebe. Um grau de calor pode se compor com um grau de branco, ou com outro grau de calor, para formar uma terceira individualidade única que não se confunde com aquela do sujeito". (Deleuze \& Guattari 4, p.309)
Com as indicações disponíveis até agora, já se pode adiantar que, à pergunta: "o que é a individualidade de um dia, de uma estação, ou de um acontecimento?" (Deleuze \& Guattari 4,p.309-310), os autores responderão que esta se faz por hecceidade, que ela configura uma intensidade. Agora, veremos que, se o termo hecceidade denota que os autores buscaram elementos em Duns Scoto (cf. Deleuze \& Guattari 4, p.318, nota de rodapé 24) para compor sua teoria da individualidade, a definição deste termo nos levará de volta à leitura deleuziana de Espinosa.

As hecceidades designam a singularidade dos acontecimentos. Assim, por exemplo, as estações, horas, datas são hecceidades porque são dotadas de "uma individualidade perfeita à qual não falta nada", mesmo que não possamos defini-las nem como coisas nem como sujeitos. Sua individualidade consiste numa determinada "relação de movimento e de repouso entre moléculas ou partículas" que implica num determinado "poder de afetar e de ser afetado" (Deleuze \& Guattari 4, p.318). Em todas as ocasiões em que Deleuze procura definir o que seria um indivíduo para Espinosa (cf. Deleuze \& Guattari 4, p.314 e 318), utiliza essas mesmas expressões, o que atesta o transporte direto de noções colhidas da sua compreensão do espinosismo para uma teoria da individualidade, elaborada em colaboração com Guattari, que fornece as bases para uma teoria da arte concomitante que compreende a produção artística como produção de intensidades, de diferenças atuantes na sensação (o que Deleuze e Guattari chamam de afectos e perceptos).

Este tipo de individualidade, como vimos, vale também para temperaturas, que são graus de calor, para nuances ou intensidades de uma cor, resumindo, para grandezas intensivas de modo geral. Tais intensidades podem "se compor em latitude" constituindo "um novo indivíduo, como num corpo que tem frio aqui e calor ali segundo sua longitude"; ou ainda, podem consolidar-se num mesmo indivíduo como graus de qualidades 
diferentes, "como em certas atmosferas brancas de um verão quente", em que uma determinada temperatura se compõe com uma nuance de branco. Charlotte Brontë, por exemplo, descreve tudo "em termos de vento", tanto “as pessoas", seus "rostos", quanto "os amores" (Deleuze \& Guattari 4, p.319). As próprias palavras se contaminam de uma certa qualidade eólica. Como se cada indivíduo fosse um tipo diferente de vento, com velocidade, umidade e temperatura próprias.

O caráter ocasional ou circunstancial que se depreende da descrição dessas individualidades não deve induzir a considerá-las como circunscritas ao instantâneo e nem como mero pano de fundo para os sujeitos, objetos e formas em geral. Uma hecceidade "não é de modo algum uma individualidade pelo instante, que se oporia àquela das permanências e das durações" (Deleuze \& Guattari 4, p.319). Não se trata de um mesmo tempo mensurável que é mais curto ou mais longo conforme o tipo de individuação considerada. Ao contrário, cada tipo de individuação implica uma temporalidade diferente. Utilizando a terminologia desenvolvida em Logique du sens, o tempo dos acontecimentos puros, independentemente de sua efetuação num estado de coisas, ou seja, a temporalidade em questão numa individuação de tipo hecceidade, é chamada de aiônica (cf. Deleuze \& Guattari 4, p.320), remetendo a um tempo liberado da tarefa de medir o movimento e da submissão estrita à sucessão. No entanto, não são apenas ressonâncias estóicas que se fazem presentes nesta concepção do tempo. Podemos apontar, embora Deleuze e Guattari não o façam em Mille plateux, para uma vizinhança de Aion com relação à eternidade espinosana, na medida em que se trata de uma temporalidade que não pode ser remetida à duração e nem, consequentemente, à sucessão. Como que aludindo à idéia proustiana, aparentemente paradoxal, de um instante de eternidade, instante em que, através da memória involuntária, podese ter acesso ao que Proust chama de puras essências, e que poderíamos igualmente chamar de ser do sensível ou intensidades.
O título do artigo mencionava a passagem de uma física do intensivo uma estética do intensivo, aludindo a uma possível compreensão da capacidade de produção humana em arte, ou seja, exprimindo novas maneiras de pensar, de sentir e de perceber, como parte intensiva ou grau da potência produtiva da Natureza. Uma tal estética uniria os dois sentidos que o termo tem assumido na história da filosofia, referindo-se tanto às condições transcendentais (e também genéticas) da sensibilidade, quanto aos juízos a respeito do que lhe apraz ou transtorna, juízos que exprimiriam afectos. Isto incluiria a criação de conceitos que possam corresponder às diferentes maneiras que as variadas formas artísticas modulam nossa capacidade de ser afetados. Tal unificação da estética seria possível porque as intensidades são aquilo que se antecipa à própria percepção e, portanto a engendra - elas são (o que se nos antepõe e configura para nós qualidades que circunscrevem objetos ou objetificações - além de ser também o que é produzido pelas obras de arte). As artes, como um dos modos do pensar, atacam-nos com problemas sensíveis, suscitando, fazendo nascer novas formas de perceber e de sentir. Se à filosofia pertence a tarefa de pensar, com conceitos, o impensável - ou o que não pode ser pensado segundo um modelo previamente estabelecido (notadamente o da recognição) - à arte cabe engendrar uma sensibilidade tampouco conformada a um papel já dado, que amplie os limites do corpo e se acompanhando de uma expansão correspondente do pensamento ${ }^{4}$.

\section{REFERÊNCIAS BIBLIOGRÁFICAS:}

1. DELEUZE, G. Diferença e repetição. Rio de Janeiro, Graal, 1988. Tradução de Luiz Orlandi e Roberto Machado. Edição original Différence et répétition, Paris, PUF, 1968.

2. A ideia de gênese na estética de Kant. In: A ilha deserta. São Paulo, Iluminuras, 2006, pp. 79-97. Tradução de Cíntia Vieira da Silva.

3._. Spinoza et le problème de l'expression, Paris, Minuit, 1968. 
5. KANT. Crítica da razão pura. Lisboa, Fundação Calouste Gulbenkian, 1994. Tradução de Manuela Pinto dos Santos.

6. MENGUE, Philippe, Gilles Deleuze ou le système du multiple, Paris, Kimé, 1994.

\section{FROM THE PHYSICS OF THE INTENSIVE TO AN AESTHETICS OF INTENSIVE: DELEUZE AND THE SINGULAR ESSENCE IN SPINOZA}

Abstratct: The notion of intensity is extremely important for Deleuzian thought, being present not only on the elaboration of his philosophy of difference, but also on his readings of the philosophers which are dear to him, specially on his reconstruction of Spinozism. Deleuze conceives Spinoza's singular essence in intensive terms. Considering these aspects, this paper seeks to gather elements to show the importance of the notion of intensity to the Deleuzian project of unifying the two senses of aesthetics and the role of Spinozist conceptions for the Deleuzian enterprise. These notes state indirectly another theme: the possibility of elaborating a spinozist Aesthetics, that is Aesthetics attentive to its bodily anchorage.

Keywords: Spinoza, Deleuze, Aesthetics, Intensity, Body.

\section{NOTAS:}

1. Sob o risco de excesso de didatismo, e de explicar algo que talvez o leitor já tenha compreendido, explicito o ponto em que o livro de Zourabichvili serve de inspiração a este artigo. Sabe-se que a palavra "física" tem sido utilizada para designar as investigações em torno da matéria, o estudo dos corpos. Se o autor fala em uma física do pensamento, é para dar ênfase à inserção das ideias, como modos do pensamento, na natureza. As ideias, como integrantes da physis, devem constituir o objeto de uma física, compreendida como ciência das transformações, o que se faz por meio de uma retomada da noção de forma. De maneira análoga, proponho a passagem de uma física do intensivo para uma estética do intensivo, considerando que a extensão não é a única dimensão da natureza, a qual inclui igualmente um aspecto intensivo. Tal distinção, entre extenso e intenso, revela-se mais interessante do que as dualidades entre uma dimensão material e outra ideal ou imaterial, entre exterioridade e interioridade, porque mantém a unidade substancial da natureza, evitando os embaraços em que recaem as hipóteses dualistas, ao procurarem explicar a união entre substâncias diferentes e as interações entre elas.

2. Deleuze refere-se neste ponto a Eth., II, 15,prop. e dem. (Deleuze 1, p. 174, nota 3).

3. Nesta página, Deleuze ressalta que Espinosa "reencontra uma longa tradição escolástica, segundo a qual modus intrinsecus = gradus = intensio."

4. Corpo e pensamento, conforme a perspectiva deleuziana, que se apropria do monismo espinosista, não são substâncias diferentes, mas aspectos ou expressões de uma mesma individualidade. 